\title{
DESIGN AND SIMULATION OF FLEXURAL STRESSES OF PM COMPOSITE BEAM
}

\author{
C H. SIVARAMAKRISHNA ${ }^{1}$, YARRAPRAGADA. K.S.S. RAO ${ }^{2}$, Y. SEETHA RAMA RAO ${ }^{3}$, SCV. \\ RAMANAMURTYNAIDU $^{4} \&$ K. TARANIKANTH ${ }^{5}$ \\ ${ }^{1,5}$ Department of Mechanical Engineering, Vignan's Institute of Information Technology, Visakhapatnam, India \\ ${ }^{2}$ Aditya College of Engineering, Surampalem, India \\ ${ }^{3}$ GVP College of Engineering, Madhurawada, Visakhapatnam, India \\ ${ }^{4}$ Kallam Harinadh Reddy Institute of Technology, Guntur, India
}

\begin{abstract}
In the present work the stress behavior of laminated composite plates under compressive loading using a four-node element with six degrees of freedom at each node and translations in the $x$ and $y$ directions is done. The composite beam is designed analytically and the modeling is done in ABAQUS. In this study simulation is carried on plate starting with three layers of top location of 00angle ply laminated composite plates at clamped boundary condition. The ABAQUS results showed, on the stresses, have also been validated with comparison of numerical results.

KEYWORDS: Laminated Composite Plate, Ply-Orientation, Numerical Method, Flexural Stresses, ABAQUS
\end{abstract}

Received: Apr 09, 2019; Accepted: Apr 30, 2019; Published: Jul 31, 2020; Paper Id.: IJMPERDJUN2020554

\section{INTRODUCTION}

Composite materials are made from two or more constituent materials which are having different physical and chemical properties when compared to individual components. The composite material can be lighter, stronger and also light in weight. The reinforcement and matrix gives us composites. The Finite Element Method (FEM) is a numerical method for solving problems of engineering and mathematical physics. It is also referred to as finite element analysis (FEA).The analytical solution of this problem is generally requires the solution to boundary value problems for partial differential equations. The FEM formulation of the problem results in a system of algebraic equations. The method yields approximate values of the unknowns at discrete number of points over the domain. The simple equations that model the finite elements are then assembled into a larger system of equations that models the entire problem. FEM then uses variation methods from the calculus of variations to approximate a solution by minimizing an associated error function. After the analytical approach the results are correlated with the abaqus software to find the error for successful validation

\section{LITERATURE REVIEW}

[1] Hajianmaleki presented a review of analysis of laminated composite structures used in recent decades. [2] Yildirim used stiffness method for the solution of the purely in-plane free vibration problem of symmetric cross-ply laminated beams. A total of six degrees of freedom, four displacements and two rotations are defined for an element. The exact in- plane element stiffness matrix of $6 \times 6$ is obtained based on the transfer matrix method. The element inertia matrix consists of the concentrated masses. The sub-space iteration and Jacobi's methods are employed in the solution of the large-scale general Eigen value problem.[3] Jun et al. introduced a dynamic finite 
element method for free vibration analysis of generally laminated composite beams on the basis of first-order shear deformation theory. The influences of Poisson effect, couplings among extensional, bending and torsional deformations, shear deformation and rotary inertia are incorporated in the formulation. The dynamic stiffness matrix is formulated based on the exact solutions of the differential equations of motion governing the free vibration of generally laminated composite beam.[4] Gurban and Gupta analyzed the natural frequencies of composite tubular shafts using equivalent modulus beam theory (EMBT) with shear deformation, rotary inertia and gyroscopic effects has been modified and used for the analysis. The modifications take into account effects of stacking sequence and different coupling mechanisms present in composite materials. Results obtained have been compared with that available in the literature using different modeling. The close agreement in the results obtained clearly show that, in spite of its simplicity, modified EMBT can be used effectively for rotor-dynamic analysis of tubular composite shafts.[5] Yegao et al. presented a general formulation for free and transient vibration analysis of composite laminated beams with arbitrary lay ups and any boundary conditions. A modified variational principle combined with a multi-segment partitioning technique is employed to derive the formulation based on a general higher order shear deformation theory. [6] Qu et al. introduced a variational formulation for predicting the free, steady-state and transient vibrations of composite laminated shells of revolution subjected to various combinations of classical and non-classical boundary conditions. A modified variational principle in conjunction with a multi-segment partitioning technique was employed to derive the formulation based on the first-order shear deformation theory.

\section{METHODOLOGY}

\section{Problem Solving Procedure for Analytical Method}

The engineering elastic constants of the unidirectional graphite/epoxy lamina are

$$
E_{1}=181 \mathrm{GPa}, E_{2}=10.3 \mathrm{GPa}, v_{12}=0.28, G_{12}=7.17 \mathrm{GPa} .
$$

Compliance matrix elements are,

$$
\begin{aligned}
& S_{11}=\frac{1}{E_{1}}=\frac{1}{\left(181 \times 10^{9}\right)}=0.5525 \times 10^{-11} \mathrm{~Pa}^{-1} \\
& S_{12}=\frac{-\vartheta_{12}}{E_{1}}=\frac{-0.28}{\left(181 \times 10^{9}\right)}=-0.1547 \times 10^{-11} \mathrm{~Pa}^{-1} \\
& S_{22}=\frac{1}{E_{2}}=\frac{1}{\left(10.3 \times 10^{9}\right)}=0.9709 \times 10^{-10} \mathrm{~Pa}^{-1} \\
& S_{66}=\frac{1}{G_{12}}=\frac{1}{\left(7.17 \times 10^{9}\right)}=0.1395 \times 10^{-0.9} \mathrm{~Pa}^{-1}
\end{aligned}
$$

And the $\vartheta_{21}$ term is called the minor poission's ratio. We have the reciprocal relation ship

$$
\begin{aligned}
& \frac{\vartheta_{12}}{E_{1}}=\frac{\vartheta_{21}}{E_{2}} \\
& \vartheta_{21}=\frac{\vartheta_{12}}{E_{1}} \times E_{2} \\
& \vartheta_{21}=\frac{0.289}{\left(181 \times 10^{9}\right)} \times\left(10.3 \times 10^{9}\right)=0.01593
\end{aligned}
$$


The reduced stiffness matrix [Q] elements are

$$
\begin{aligned}
& Q_{11}=\frac{E_{1}}{1-\vartheta_{21} \vartheta_{12}}=\frac{\left(181 \times 10^{9}\right)}{1-(0.28 \times 0.01593)}=181.8 \times 10^{9} \mathrm{~Pa} \\
& Q_{12}=\frac{\vartheta_{12} E_{2}}{1-\vartheta_{21} \vartheta_{12}}=\frac{\left(0.28 \times 10.3 \times 10^{9}\right)}{1-(0.28 \times 0.01593)}=2.897 \times 10^{9} \mathrm{~Pa} \\
& Q_{22}=\frac{E_{2}}{1-\vartheta_{21} \vartheta_{12}}=\frac{\left(10.3 \times 10^{9}\right)}{1-(0.28 \times 0.01593)}=10.35 \times 10^{9} \mathrm{~Pa}
\end{aligned}
$$

The compliance matrix for an orthotropic plane stress problem can be written as,

$$
\begin{aligned}
& {\left[\begin{array}{l}
\varepsilon_{1} \\
\varepsilon_{2} \\
\gamma_{12}
\end{array}\right]=\left(\begin{array}{ccc}
S_{11} & S_{12} & 0 \\
S_{12} & S_{22} & 0 \\
0 & 0 & S_{66}
\end{array}\right)\left[\begin{array}{l}
\sigma_{1} \\
\sigma_{2} \\
\tau_{12}
\end{array}\right]} \\
& {\left[\begin{array}{l}
\varepsilon_{1} \\
\varepsilon_{2} \\
\gamma_{12}
\end{array}\right]=\left(\begin{array}{ccc}
0.5525 \times 10^{-11} & -0.1547 \times 10^{-11} & 0 \\
-0.1547 \times 10^{-11} & 0.9709 \times 10^{-10} & 0 \\
0 & 0 & 0.1395 \times 10^{-09}
\end{array}\right)\left\{\begin{array}{l}
2 \times 10^{6} \\
-3 \times 10^{6} \\
4 \times 10^{6}
\end{array}\right\}=\left\{\begin{array}{l}
15.691 \times 10^{-6} \\
-294.364 \times 10^{-6} \\
558.0 \times 10^{-6}
\end{array}\right\}}
\end{aligned}
$$

Reduced stiffness matrix for $0^{\circ}$ graphite/epoxy ply is

$$
[Q]=\left(\begin{array}{ccc}
Q_{11} & Q_{12} & 0 \\
Q_{12} & Q_{22} & 0 \\
0 & 0 & Q_{66}
\end{array}\right)=\left(\begin{array}{ccc}
181.8 & 2.897 & 0 \\
2.897 & 10.35 & 0 \\
0 & 0 & 7.17
\end{array}\right) \times 10^{9} \mathrm{~Pa}
$$

The transformed reduced stiffness matrix $[\bar{Q}]$ for each of the three plies is,

$$
[\bar{Q}]=\left(\begin{array}{lll}
\bar{Q}_{11} & \bar{Q}_{12} & \bar{Q}_{16} \\
\bar{Q}_{12} & \bar{Q}_{22} & \bar{Q}_{26} \\
\bar{Q}_{16} & \bar{Q}_{26} & \bar{Q}_{66}
\end{array}\right)
$$

The transformed reduced stiffness matrix $[\bar{Q}]$ for $0^{0}$ plyis

$$
\left(\begin{array}{ccc}
181.8 & 2.897 & 0 \\
2.897 & 10.35 & 0 \\
0 & 0 & 7.17
\end{array}\right) \times 10^{9} \mathrm{~Pa}
$$

The transformed reduced stiffness matrix $[\bar{Q}]$ for $30^{0}$ plyis 


$$
\left(\begin{array}{lll}
109.4 & 32.46 & 54.19 \\
32.46 & 23.65 & 20.05 \\
54.19 & 20.05 & 36.74
\end{array}\right) \times 10^{9} \mathrm{~Pa}
$$

The transformed reduced stiffness matrix $[\bar{Q}]$ for- $45^{0}$ plyis

$$
\left(\begin{array}{ccc}
56.66 & 42.32 & -42.87 \\
42.32 & 56.66 & -42.87 \\
-42.87 & -42.87 & 46.59
\end{array}\right) \times 10^{9} \mathrm{~Pa}
$$

The total thickness of the laminate (Fig.3.2) is $\mathrm{h}=0.005 \times 3=0.015 \mathrm{~m}$ The mid plane is $0.0075 \mathrm{~m}$ from the top and the bottom of the laminate. The locations of ply surfaces are placed evenly from the surface of mid plane such that each ply is placed is oriented as shown in Fig 1,
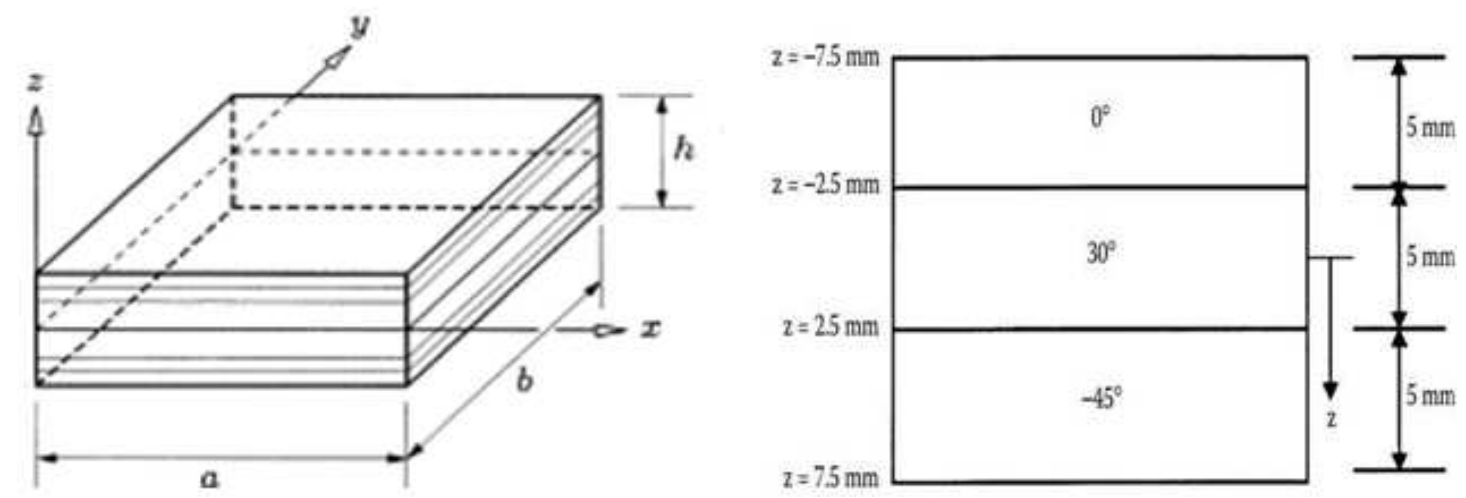

Figure 1: Schematic Diagrams of Plies.

$\mathrm{h}_{0}=-0.0075 \mathrm{~m}, \mathrm{~h}_{1}=-0.0025 \mathrm{~m}, \mathrm{~h}_{2}=+0.0025 \mathrm{~m}, \mathrm{~h}_{3}=+0.0075 \mathrm{~m}$

The Extensional stiffness matrix [A]

$$
[A]=\left(\begin{array}{ccc}
1.739 \times 10^{9} & 3.884 \times 10^{8} & 5.663 \times 10^{7} \\
3.884 \times 10^{8} & 4.533 \times 10^{8} & -1.141 \times 10^{8} \\
5.663 \times 10^{7} & -1.141 \times 10^{8} & 4.525 \times 10^{8}
\end{array}\right) P a-m
$$

Coupling stiffness matrix [B]

$$
\begin{aligned}
& B_{i j}=\frac{1}{2} \sum_{k=1}^{3}\left[\bar{Q}_{i j}\right]_{k}\left(\mathrm{~h}_{k}^{2}-\mathrm{h}_{k-1}^{2}\right) ; \mathrm{i}=1,2,6 ; \mathrm{j}=1,2,6 ; \\
& {[B]=\left(\begin{array}{ccc}
-3.129 \times 10^{6} & 9.855 \times 10^{5} & -1.072 \times 10^{6} \\
9.855 \times 10^{5} & 1.158 \times 10^{6} & -1.072 \times 10^{6} \\
-1.072 \times 10^{6} & -1.072 \times 10^{6} & 9.855 \times 10^{5}
\end{array}\right) P a-m^{2}}
\end{aligned}
$$

The bending stiffness matrix [D] 


$$
\begin{aligned}
& D_{i j}=\frac{1}{3} \sum_{k=1}^{3}\left[\bar{Q}_{i j}\right]_{k}\left(\mathrm{~h}_{k}^{3}-\mathrm{h}_{k-1}^{3}\right) ; \mathrm{i}=1,2,6 ; \mathrm{j}=1,2,6 ; . \\
& {[D]=\left(\begin{array}{ccc}
3.343 \times 10^{4} & 6.461 \times 10^{3} & -5.240 \times 10^{3} \\
6.416 \times 10^{3} & 9.320 \times 10^{3} & -5.596 \times 10^{3} \\
-5.240 \times 10^{3} & -5.596 \times 10^{3} & 7.663 \times 10^{3}
\end{array}\right) P a-m^{3}} \\
& \left\{\begin{array}{l}
k_{x} \\
k_{y} \\
k_{x y}
\end{array}\right\}=\left[C^{\prime}\right]\left\{\begin{array}{l}
N_{x} \\
N_{y} \\
N_{x y}
\end{array}\right\}=\left\{\begin{array}{l}
2.97 \times 10^{-2} \\
-3.2842 \times 10^{-3} \\
4.105 \times 10^{-1}
\end{array}\right\} 1 / \mathrm{m}
\end{aligned}
$$

By using following relations to find strains and curvatures of each ply with different orientations,

The laminate strains can be written as,

$$
\left\{\begin{array}{l}
\varepsilon_{x} \\
\mathcal{E}_{y} \\
\gamma_{x y}
\end{array}\right\}=\left\{\begin{array}{l}
\varepsilon_{x}^{0} \\
\varepsilon_{y}^{0} \\
\gamma_{x y}^{0}
\end{array}\right\}+Z\left\{\begin{array}{l}
K_{X} \\
K_{Y} \\
K_{X Y}
\end{array}\right\}
$$

Find the strains where $\mathrm{Z}=-0.0025 \mathrm{~mm}$ for $30^{\circ}$ angle ply

$$
\begin{aligned}
& =\left\{\begin{array}{l}
3.126 \times 10^{-4} \\
3.4916 \times 10^{-5} \\
-7.60188 \times 10^{-4}
\end{array}\right\}+(-0.0025)\left\{\begin{array}{l}
2.97 \times 10^{-2} \\
-3.2842 \times 10^{-3} \\
4.105 \times 10^{-1}
\end{array}\right\} \\
& \left\{\begin{array}{l}
\varepsilon_{x} \\
\varepsilon_{y} \\
\gamma_{x y}
\end{array}\right\}=\left\{\begin{array}{l}
2.3835 \times 10^{-4} \\
4.31265 \times 10^{-5} \\
-1.78643 \times 10^{-3}
\end{array}\right\} m / m
\end{aligned}
$$

And using stress-strain relation for Top location of $30^{\circ}$ ply

$$
\begin{aligned}
& {\left[\begin{array}{l}
\sigma_{x} \\
\sigma_{y} \\
\tau_{x y}
\end{array}\right]=\left(\begin{array}{lll}
\bar{Q}_{11} & \bar{Q}_{12} & \bar{Q}_{16} \\
\bar{Q}_{12} & \bar{Q}_{22} & \bar{Q}_{26} \\
\bar{Q}_{16} & \bar{Q}_{26} & \bar{Q}_{66}
\end{array}\right)\left\{\begin{array}{l}
\varepsilon_{x} \\
\varepsilon_{y} \\
\gamma_{x y}
\end{array}\right\}} \\
& =\left[\begin{array}{lll}
109.4 & 32.46 & 54.19 \\
32.46 & 23.65 & 20.05 \\
54.19 & 20.05 & 36.74
\end{array}\right] \times 10^{9}\left\{\begin{array}{c}
2.3835 \times 10^{-4} \\
4.31265 \times 10^{-5} \\
-1.78643 \times 10^{-3}
\end{array}\right\} \\
& =\left\{\begin{array}{c}
6.93 \times 10^{7} \\
7.495 \times 10^{5} \\
3.676 \times 10^{7}
\end{array}\right\}
\end{aligned}
$$

The Numerical results are compared with simulated results to estimate the percentage of error for validation. The defined problem was solved using Numerical method, the results are tabulated and same was analyzed using FEM based 
ABAQUS Software and the results are shown in Fig 2.

\section{Stress Analysis of Composite Ply at Orientation of $\left[0^{0} / 30^{0} /-45^{0}\right]$}

The ply at $\left[0 \% 30^{0} /-45^{0}\right]$ orientation is analyzed in $\mathrm{x}$-direction $\mathrm{Y}$-direction and in xy-direction (shear), results obtained are as follows,

Table 1

\begin{tabular}{|l|c|c|}
\hline X-direction & $\sigma_{\mathrm{x}}$ & $6.93 \times 10^{7} \mathrm{~Pa}$ \\
\hline Y-direction & $\sigma_{\mathrm{y}}$ & $7.495 \times 10^{5} \mathrm{~Pa}$ \\
\hline $\mathrm{XY}$-direction & $\tau_{\mathrm{xy}}$ & $3.676 \times 10^{7} \mathrm{~Pa}$ \\
\hline
\end{tabular}

The results obtained through ABAQUS solving are as follows,

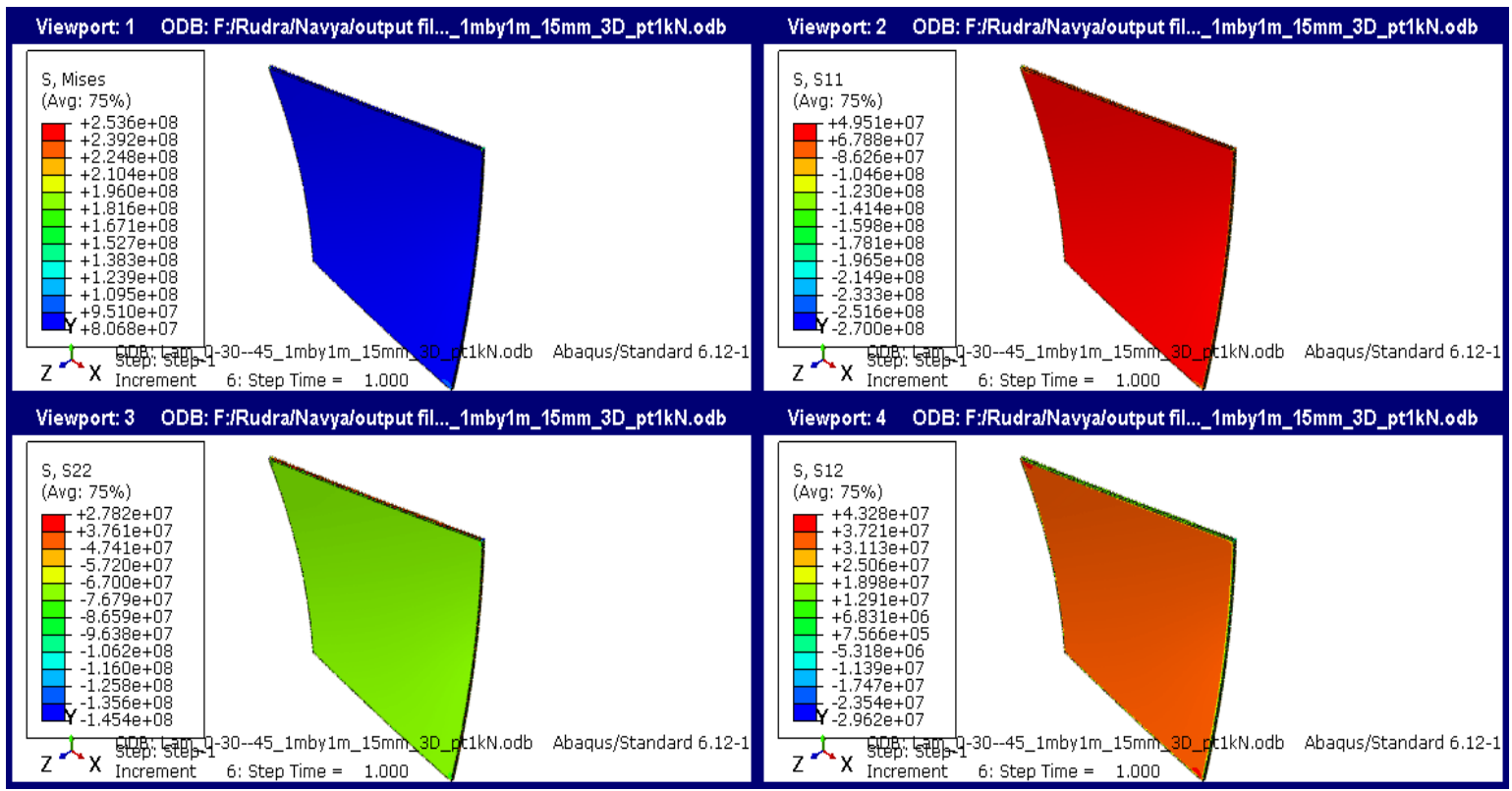

Figure 2: Stress on $\left[0^{0} / 30^{0} /-45^{0}\right]$ Composite.

\section{RESULTS \& DISCUSSIONS}

The table below shows the values of stresses between numerical and simulated values of a composite beam. This result helps to estimate the percentage of error in numerical and simulated methods.

Table 2: Comparison of Results for Validation for $\left[0^{0} / 30^{0} /-45^{0}\right]$ Ply Orientation

\begin{tabular}{|c|l|c|c|c|}
\hline \multirow{2}{*}{ S. No } & \multirow{2}{*}{ Design Parameter } & \multicolumn{2}{|c|}{ Results } & Percentage of Error (\%) \\
\cline { 3 - 5 } & & Analytical Method Simulated Method & A & \\
\hline 1 & Stress in X Direction $(\mathrm{Pa})$ & $6.93 \times 10^{7}$ & $6.788 \times 10^{7}$ & 2.19 \\
\hline 2 & Stress in Y Direction $(\mathrm{Pa})$ & $7.495 \times 10^{5}$ & $7.566 \times 10^{5}$ & 0.938 \\
\hline 3 & Shear Stress $(\mathrm{Pa})$ & $3.676 \times 10^{7}$ & $3.761 \times 10^{7}$ & 2.26 \\
\hline
\end{tabular}

From the above table, it is concluded that the percentage error between analytical and simulated is less. Hence the values are validated.

\section{CONCLUSIONS \& FUTURE SCOPE OF WORK}

Layered composite was successfully analyzed using Finite Element Analysis and simulated using ABAQUS software. The three plies of laminated Graphite/Epoxy are subjected to bending loads along both $\mathrm{x}$ and y directions. The bending stresses 
are calculated through numerical method and simulation method using ABAQUS. The results are compared the in estimating error .The observed error is with less value hence the results are validated. The same work is extended with other analysis tools for better accuracy

\section{REFERENCES}

1. M.Hajianmaleki and M.S.Qatu, Vibrations of straight and curved composite beams: A review, Composite Structures, Vol. 100, pp 218-232, 2013.

2. Tharun, Boorla, and SreenuRamavath. "Influence of Transverse Hole on Flexural Strength of RC Beam. "International Journal of Civil Engineering (IJCE) 8. 1, Dec- Jan 2019; 1-12

3. V.Yildirim, Effect of the longitudinal to transverse moduli ratio on the in-plane natural frequencies of symmetric cross-ply laminated beams by the stiffness method, Composite structures, vol.50, pp.319-326,2000.

4. L.Jun, H.Hongxing and S.Rongying, Dynamic finite element method for generally laminated composite beams, Int. J.Mechanical Sciences, vol.50, pp.466-480,2008.

5. George, Raiza Susan, and Nivin Philip. "A Review on Stress Block Parameters of High Performance Concrete. "International Journal of Civil Engineering (IJCE) 5. 6, Oct - Nov 2016; 25-32

6. H.B.H.Gubran and K.Gupta, The effect of stacking sequence and coupling mechanisms on the natural frequencies of composite shafts, J.Sound and Vibration, vol.282, pp.231- 248, 2005.

7. Baviskar, V. R., et al. "Static analysis of master leaf spring." IJRET: International Journal of Research in Engineering and Technology, eISSN (2014): 2319-1163.

8. Yegao Qu, Xinhua Long, Hongguang Li, GuangMeng, A variational formulation for dynamic analysis of composite laminated beams on a general higher-order shear deformation theory, Composite Structures, Vol. 102 ,175-192, 2013.

9. Kesavarao, Yenda, Ch Ramakrishna, and AineelkamalArji. "Stress Analysis of Laminated Graphite/Epoxy Composite Plate Using FEM." International Journal of Mechanical Engineering (IJME) 4 (2015): 5.

10. Y.Qu, X.Long, S.Wu and G.Meng, A unified formulation for vibration analysis of composite laminated shells of revolution including shear deformation and rotary inertia, Composite structures, Vol.98, pp.169-191,2013. 

